\title{
Social Distancing and COVID-19: Correspondence
}

\author{
Himanshu Agrawal ${ }^{1}$, Sweta Singh ${ }^{2}$, Nikhil Gupta $^{3}$, Binita Goswami ${ }^{4}$
}

\begin{abstract}
Social distancing (SD) has been promoted by countries around the world as an effective way to stop the transmission chain. Recently, the word physical distancing is promoted in place of SD, as people are encouraged to connect with each other on a social platform. The term SD although introduced in 21 st century, its implication dates back to 5 th century BC. The Book of Leviticus in Bible contains the earliest reference for social distancing.
\end{abstract}

Keywords: Aerosols, Highly infectious disease, Physical contact.

Indian Journal of Medical Biochemistry (2020): 10.5005/jp-journals-10054-0152

Coronavirus disease 2019 (COVID-19) is a highly infectious disease caused by severe acute respiratory syndrome coronavirus-2 (SARSCov-2). This virus is the seventh human coronavirus identified till date. The main spread of this virus is through-

- Aerosols: When an infected person coughs or sneezes, virusladen particles are expelled at a rate of around $40 \mathrm{~km} / \mathrm{hour}$ and $160 \mathrm{~km} /$ hour, respectively. The larger particles travel for up to $2 \mathrm{~m}$ and fall on to ground almost instantly, while the smaller particles can travel for up to $6 \mathrm{~m}$ and can remain suspended in air for about 10 minutes in a well-ventilated area and for several hours in non-ventilated and enclosed spaces. ${ }^{1}$

- Physical contact: When virus-laden particles fall on a surface, it can survive on it for a variable time. This can cause transmission to other non-infected individuals. ${ }^{2}$

- Feco-oral route: Virus particles have been known to found in feces and thus can be a potential mode of transmission.

Preventing the man-to-man transmission of this virus is the only way to effectively control this pandemic. Social distancing (SD) has been promoted by countries around the world as an effective way to stop the transmission chain. It involves keeping a certain distance from each other and avoiding gatherings in large groups. Recently, the word physical distancing is promoted in place of SD, as people are encouraged to connect with each other on a social platform. Although the term SD was introduced in 21st century, its implication dates back to 5 th century BC. The Book of Leviticus in Bible contains the earliest reference for SD. It states "and the leper in whom the plague is, he shall dwell alone, the camp shall his habitation be". Later, during the Plague of Justinian (541 to 542), emperor Justinian enforced quarantine on the Byzantine Empire, including dumping bodies into the sea. Since then, SD has been implicated in various epidemics and pandemics like New York city polio epidemic in 1916, influenza pandemic in 1918, SARS outbreak in 2003, flu pandemic in 2019, and the most recent being COVID-19 pandemic. SD not only implies to avoid physical contact and maintaining appropriate distance from each other, but it also includes other measure such as closure of schools and workplaces, avoiding mass gatherings, and travel restrictions. Quarantine of suspects is also another aspect of SD.

\section{Social Distancing in COVID-19}

World Health Organization described SD during the $2009 \mathrm{flu}$ pandemic as "keeping at least an arm's length distance from others and minimizing gatherings". ${ }^{3}$ During the COVID-19 pandemic, the
${ }^{1,3}$ Department of Surgery, Atal Bihari Vajpayee Institute of Medical Sciences and Dr. Ram Manohar Lohia Hospital, New Delhi, India

${ }^{2}$ Department of Dermatology, Atal Bihari Vajpayee Institute of Medical Sciences and Dr. Ram Manohar Lohia Hospital, New Delhi, India

${ }^{4}$ Department of Biochemistry, Maulana Azad Medical College, New Delhi, India

Corresponding Author: Himanshu Agrawal, Department of Surgery, Atal Bihari Vajpayee Institute of Medical Sciences and Dr. Ram Manohar Lohia Hospital, New Delhi, India, Phone: +91 9999472790, e-mail: himagr1987@gmail.com

How to cite this article: Agrawal H, Singh S, Gupta N, et al. Social Distancing and COVID-19: Correspondence. Indian J Med Biochem 2020;24(2):87-88.

Source of support: Nil

Conflict of interest: None

Centre for Disease Control and Prevention defined social distancing as "avoiding mass gatherings and maintaining approximately six feet or two meters from others when possible". When this is combined with hand washing practices and good respiratory hygiene, it is considered the most feasible way to limit human to human transmission.

Since virus particle can travel up to $6 \mathrm{~m}$, this figure of $2 \mathrm{~m}$ chosen seem to be questionable.

Social distancing although linked to have a positive outcome in COVID-19 pandemic is also associated with some serious repercussions. First, it comes with an economic cost to every sector of the community. There is a loss of currency flow and can result in serious detrimental effect on country's gross domestic product (GDP). Second, it can have an adverse effect on participant's mental health. Anxiety, stress, and depression are common outcomes, especially in people with preexisting conditions such as paranoia, obsessive compulsive disorder and anxiety disorders. ${ }^{4}$ Finally, it has also created a state of unrest in various sections of the community especially the teen age. There have been reports of protests against this from various countries such as, Belgium, France, United States, and United Kingdom.

In conclusion, it can be stated that however inconvenient SD seems, it appears to be single ray of hope during this COVID-19 pandemic. It is essential to combine it with other maneuvers such as frequent hand washing/sanitization and appropriate respiratory

(c) The Author(s). 2020 Open Access This article is distributed under the terms of the Creative Commons Attribution 4.0 International License (https://creativecommons. org/licenses/by-nc/4.0/), which permits unrestricted use, distribution, and non-commercial reproduction in any medium, provided you give appropriate credit to the original author(s) and the source, provide a link to the Creative Commons license, and indicate if changes were made. The Creative Commons Public Domain Dedication waiver (http://creativecommons.org/publicdomain/zero/1.0/) applies to the data made available in this article, unless otherwise stated. 
hygiene in an attempt to effectively flatten the COVID-19 pandemic curve.

\section{References}

1. Lee J, Yoo D, Ryu S, et al. Quantity, size distribution, and characteristics of cough-generated aerosol produced by patients with an upper respiratory tract infection. Aerosol and Air Quality Research. 2018;19(4):840-853. DOI: 10.4209/aaqr.2018.01.0031.

2. Van Doremalen N, Bushmaker T, Morris DH, et al. Aerosol and surface stability of SARS-CoV-2 as compared with SARS-CoV-1. N Engl J Med 2020;382(16):1564-1567. DOI: 10.1056/NEJMc2004973.
3. World Health Organization (WHO). Pandemic influenza prevention and mitigation in low resource communities. In Pandemic influenza prevention and mitigation in low resource communities 2008. World Health Organization (WHO).

4. Stawicki SP, Jeanmonod R, Miller AC, et al. The 2019-2020 novel coronavirus (severe acute respiratory syndrome coronavirus 2) pandemic: a joint american college of academic international medicine-world academic council of emergency medicine multidisciplinary COVID-19 working group consensus paper. J Glob Infect Dis 2020;12(2):47. DOI: 10.4103/jgid. jgid_86_20. 